\title{
Application of 3-Bromo-3-ethylazetidines and 3-Ethylideneazetidines for the Synthesis of Functionalized Azetidines
}

\author{
Sonja Stanković, Matthias D’hooghe, ${ }^{*}$ Tim Vanderhaegen, Kourosch Abbaspour Tehrani, ${ }^{1}$ Norbert De Kimpe* \\ Department of Sustainable Organic Chemistry and Technology, Faculty of Bioscience Engineering, Ghent University, Coupure Links 653 , \\ 9000 Ghent, Belgium \\ E-mail: matthias.dhooghe@UGent.be; Fax +3292646221; E-mail: norbert.dekimpe@UGent.be \\ Received: 14.08.2013; Accepted after revision: 14.10.2013
}

\begin{abstract}
The synthetic utility of 3-bromo-3-ethylazetidines has been demonstrated by the straightforward preparation of 3-alkoxy-, 3-aryloxy-, 3-acetoxy-, 3-hydroxy-, 3-cyano-, 3-carbamoyl- and 3-amino-3-ethylazetidines. In addition, 3-bromo-3-ethylazetidines have been successfully deployed as precursors for a convenient synthesis of 3-ethylideneazetidines, which served as starting materials for the preparation of novel functionalized azetidines and spirocyclic azetidine building blocks.
\end{abstract}

Key words: heterocycles, nitrogen, nucleophiles, rearrangement, ring opening, spiro compounds

Aziridines and azetidines belong to an intriguing group of small-ring azaheterocycles with interesting properties and a great potential from both a synthetic ${ }^{2}$ and a biological ${ }^{3}$ point of view. Azetidines, which have been studied to a lesser extent than aziridines, are accessible via established synthetic routes including ring closure of $\gamma$-haloamines and reduction of $\beta$-lactams, ${ }^{2 j, k, 4}$ although other general approaches such as addition of nucleophiles across $\beta$-haloimines followed by ring closure ${ }^{5}$ and Mannich-type reactions of functionalized imines ${ }^{6}$ have been designed. 3-Alkylideneazetidines are strained cyclic allylamines, and very limited information on the reactivity of this peculiar class of azetidine compounds is available in the literature. ${ }^{7}$ In most cases, the 3-alkylideneazetidine moiety has been incorporated in the structure of more complex molecules, ${ }^{8}$ and no special attention has been devoted to the chemical nature and synthetic applicability of these systems so far. The two main literature approaches to introduce an alkylidene functionality at the 3-position of an azetidine ring comprise Wittig olefination of the corresponding azetidin-3-ones ${ }^{7 b, d, e}$ and dehydrohalogenation of 3-halo-3-(haloalkyl)azetidines. ${ }^{7 \mathrm{~d}}$

In continuation of our interest in the study of 3-haloazetidines as synthons in organic chemistry, ${ }^{9} 3$-bromo-3-ethylazetidines were prepared in this work and evaluated as suitable substrates to enable nucleophilic bromide displacement leading to functionalized 3 -ethylazetidines and dehydrobromination as an entry to novel 3-ethylideneazetidines. Furthermore, the behavior of this 3-ethylideneazetidine scaffold was then assessed with respect to different reagents in order to reveal new synthetic path-

SYNLETT 2014, 25, 0075-0080

Advanced online publication: 04.12.2013

DOI: 10.1055/s-0033-1340250; Art ID: ST-2013-D0780-L

C Georg Thieme Verlag Stuttgart · New York ways toward functionalized azetidines. It should be mentioned that the synthesis and reactivity study of structurally related 2-alkylideneazetidines, which behave as cyclic enamines, has been the subject of previous reports. ${ }^{10,11}$ These azetidines have been shown to be eligible substrates in various cycloaddition reactions and ring rearrangements.

However, it was expected that 3-alkylideneazetidines, which can be regarded as cyclic allylamines, would exhibit a totally different reactivity profile as compared to 2-alkylideneazetidines due to the presence of a rather inactive and sterically hindered double bond. The reactivity of both the azetidine ring and the olefenic moiety has been assessed in this study.

In accordance with the previously described synthesis of 3-bromo-3-methylazetidines, 3-bromo-3-ethylazetidines 3a,b were prepared starting from 2-bromomethyl-2-ethylaziridines 2a,b, themselves obtained by a three-step approach $^{12}$ involving bromination of 2-ethylpropenal (1) using $\mathrm{Br}_{2}$ in $\mathrm{CH}_{2} \mathrm{Cl}_{2}$, imination with primary $N$-(arylmethyl)amines in the presence of $\mathrm{TiCl}_{4}$ and $\mathrm{Et}_{3} \mathrm{~N}$ in $\mathrm{Et}_{2} \mathrm{O}$, and reduction of the corresponding $\alpha, \beta$-dibromoimines by means of $\mathrm{NaBH}_{4}$ in $\mathrm{MeOH}$ (Scheme 1). Heating aziridines 2 in $\mathrm{MeCN}$ under reflux for 15 hours afforded the desired novel 3-bromo-3-ethylazetidines 3a,b in nearly quantitative yields. A similar aziridine to azetidine ring rearrangement of 2-bromomethyl-2-methylaziridines has previously been shown to occur via intermediacy of bicyclic aziridinium species, which were opened at the more hindered carbon atom to provide the corresponding 3-bromo-3-methylazetidines. ${ }^{12}$

In contrast to the synthesis of 1-arylmethyl-3-bromo3 -ethylazetidines 3 , obtained through rearrangement of 2-bromomethyl-2-ethylaziridines 2 , the formation of 3bromo-1-tert-butyl-3-ethylazetidine (5) proceeded via $\beta, \gamma$-dibromoamine 4 , formed through consecutive treatment of 2-ethylpropenal (1) with bromine, tert-butylamine and sodium borohydride (Scheme 1). Heating a solution of the $\beta, \gamma$-dibromoamine 4 in $i$-PrOH under reflux for 16 hours followed by basic workup induced cyclization to the target 3-bromo-3-ethylazetidine 5 .

It should be mentioned that 3-bromo-3-ethylazetidines $\mathbf{3}$ represent eligible substrates for nucleophilic bromide displacements, as was the case for their structurally related 3-bromo-3-methylazetidines. ${ }^{9 a}$ 

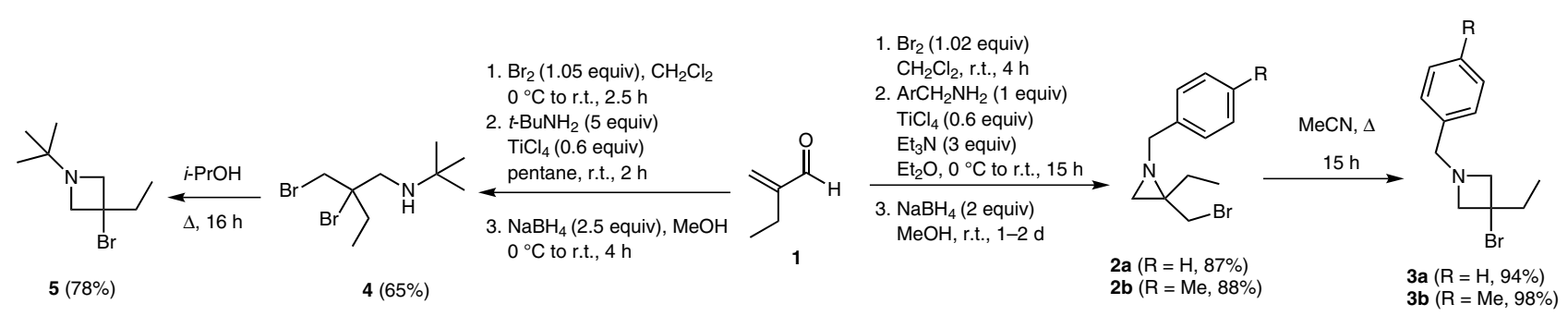

Scheme 1

For example, the reactions of $\mathbf{3 a}, \mathbf{b}$ with oxygen nucleophiles, such as methoxide $\left[\mathrm{NaBH}_{4}\right.$ (2 equiv), $\mathrm{MeOH}, \Delta$, $2 \mathrm{~d}]$, phenoxide [ $\mathrm{PhOH}$ (2.2 equiv), $\mathrm{K}_{2} \mathrm{CO}_{3}$ (5 equiv), $\mathrm{MeCN}, \Delta, 1 \mathrm{~d}$ ], sodium acetate [ $\mathrm{NaOAc}$ ( 5 equiv), $\mathrm{MeCN}$, $\Delta, 3-5 \mathrm{~d}]$ and potassium hydroxide [ $\mathrm{KOH}$ (5 equiv), $\mathrm{H}_{2} \mathrm{O} / \mathrm{CH}_{2} \mathrm{Cl}_{2}$ (7:1), $\Delta, 15-20 \mathrm{~h}$ ], provided the corresponding 3-alkoxy-, 3-aryloxy-, 3-acetoxy- and 3-hydroxy3-ethylazetidines 6a-d $(\mathrm{Nu}=\mathrm{OMe}, \mathrm{OPh}, \mathrm{OAc}, \mathrm{OH})$, respectively (Scheme 2). The reaction of 3a with $n$-propylamine furnished 3-propylaminoazetidine $6 \mathbf{e}[\mathrm{Nu}=n$-PrNH; $n$ - $\mathrm{PrNH}_{2}$ (5 equiv), MeCN, $\Delta, 1 \mathrm{~d}$ ], while azetidines $\mathbf{3 a}, \mathbf{b}$ gave 3-cyanoazetidines $\mathbf{6} \mathbf{f}, \mathbf{f}^{\prime}$ on treatment with potassium cyanide $[\mathrm{KCN}$ (1.5 equiv), $\mathrm{MeCN}, \Delta, 1 \mathrm{~d}]$.

Further reaction of azetidine-3-carbonitrile $6 \mathbf{f}$ with $\mathrm{KOH}$ (5 equiv) in $\mathrm{EtOH} / \mathrm{H}_{2} \mathrm{O}(10: 1)$ under microwave irradiation $\left(10 \mathrm{~min}, 150{ }^{\circ} \mathrm{C}, 150 \mathrm{~W}\right)$ resulted in amide 7 as the major compound $(77 \%)$, accompanied by a small amount of the corresponding amino acid 8 (19\%; Scheme 2). The formation of carboxylic acid $\mathbf{8}$ was evidenced upon neutralization of the reaction mixture to $\mathrm{pH} 7$ using $1 \mathrm{M} \mathrm{HCl}$. Attempts to develop an effective synthesis of amino acid $\mathbf{8}$ by prolonging the reaction time (up to $2 \mathrm{~h}$ ) proved to be unsuccessful.

In summary, the above-described findings acknowledge the suitability of 3-bromo-3-ethylazetidines as substrates for nucleophilic substitutions by different oxygen-, nitrogen- and carbon-centered nucleophiles.

In the next part of our studies, the eligibility of 3-bromo3-ethylazetidines as substrates for the preparation of the corresponding new 3-ethylideneazetidines was investigated. Whereas the dehydrobromination of 3-bromo-1-tertbutylazetidine 5 utilizing $t$-BuOK (1.5 equiv) in THF af- forded 1-tert-butyl-3-ethylideneazetidine (9) in a good yield (Scheme 3), the synthesis of 1-arylmethyl-3-ethylideneazetidines 10a,b starting from 3-bromo-3-ethylazetidines 3a,b was not as straightforward as initially anticipated, and several attempts were performed to optimize the reaction conditions. Treatment of azetidine $\mathbf{3 a}$ with different bases such as $t$-BuOK, LDA and $\mathrm{NaH}$ in $\mathrm{THF}$ at room temperature or under reflux gave no reaction, and addition of $t$ - $\mathrm{BuOK}$ in $t$ - $\mathrm{BuOH}$ under reflux resulted in a mixture of different compounds. Eventually, the use of 1.5 equivalents of $t$ - $\mathrm{BuOK}$ in THF and heating under microwave irradiation for ten minutes at $120^{\circ} \mathrm{C}$ selectively provided 3-ethylideneazetidines $\mathbf{1 0 a}, \mathbf{b}$ in excellent yields (Scheme 3). ${ }^{13}$

The reactivity study of 3-ethylideneazetidines was expected to be a quite challenging task bearing in mind the sterically hindered and poorly reactive double bond. Prior to evaluating the intrinsic reactivity of this olefinic moiety, the propensity of the azetidine ring to undergo ring opening was investigated. Due to the presence of an electron-donating alkyl group at nitrogen, activation of the azetidine ring toward an azetidinium species is necessary to effect ring-opening processes. N-Acetylation of alkylideneazetidine 10a with 1.5 equivalents of acetyl chloride in $\mathrm{CH}_{2} \mathrm{Cl}_{2}$ and subsequent ring opening by the displaced chloride ion afforded a mixture of $(E)$ - and (Z)-allylamines $12(\mathrm{E}=\mathrm{MeCO}, \mathrm{X}=\mathrm{Cl}, E / Z=1: 1)$ after 15 hours under reflux (Table 1, Scheme 3 ). In a similar manner, the reaction of 10a with one equivalent of benzyl bromide in $\mathrm{MeCN}$ gave the corresponding allylamines 13 (Table 1, E $=\mathrm{Bn}, \mathrm{X}=\mathrm{Br}, E / Z=3: 2$ or vice versa) after 15 hours under reflux. These reactions were straightforward and resulted in a complete conversion of the starting material, although

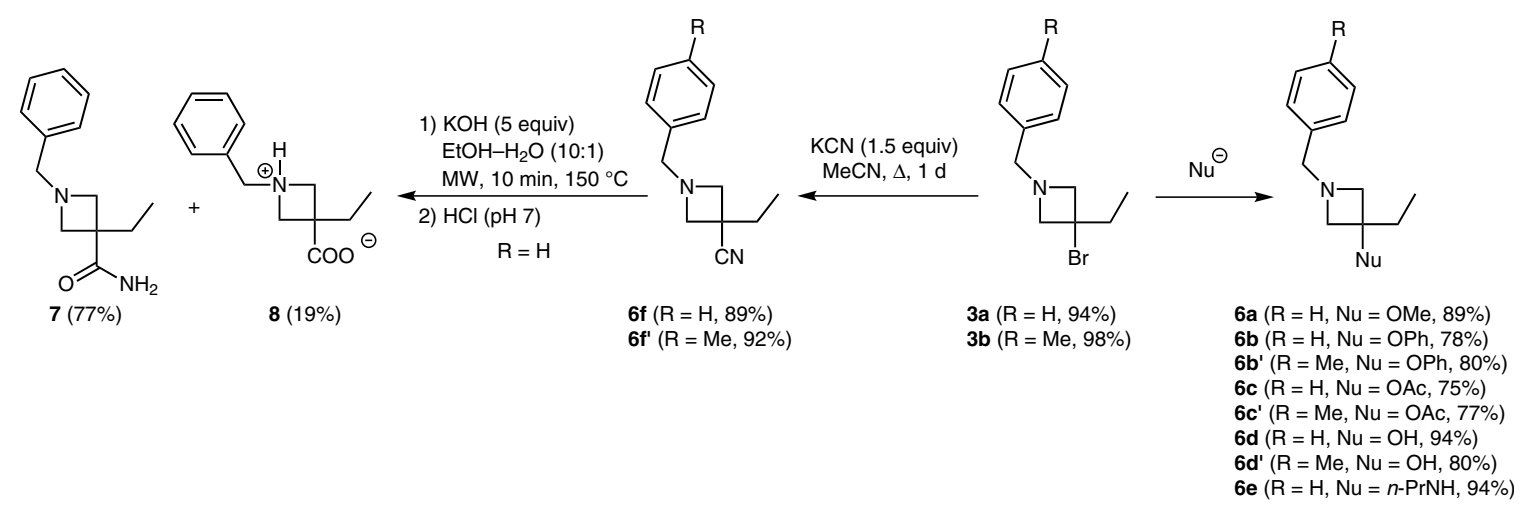

Scheme 2 


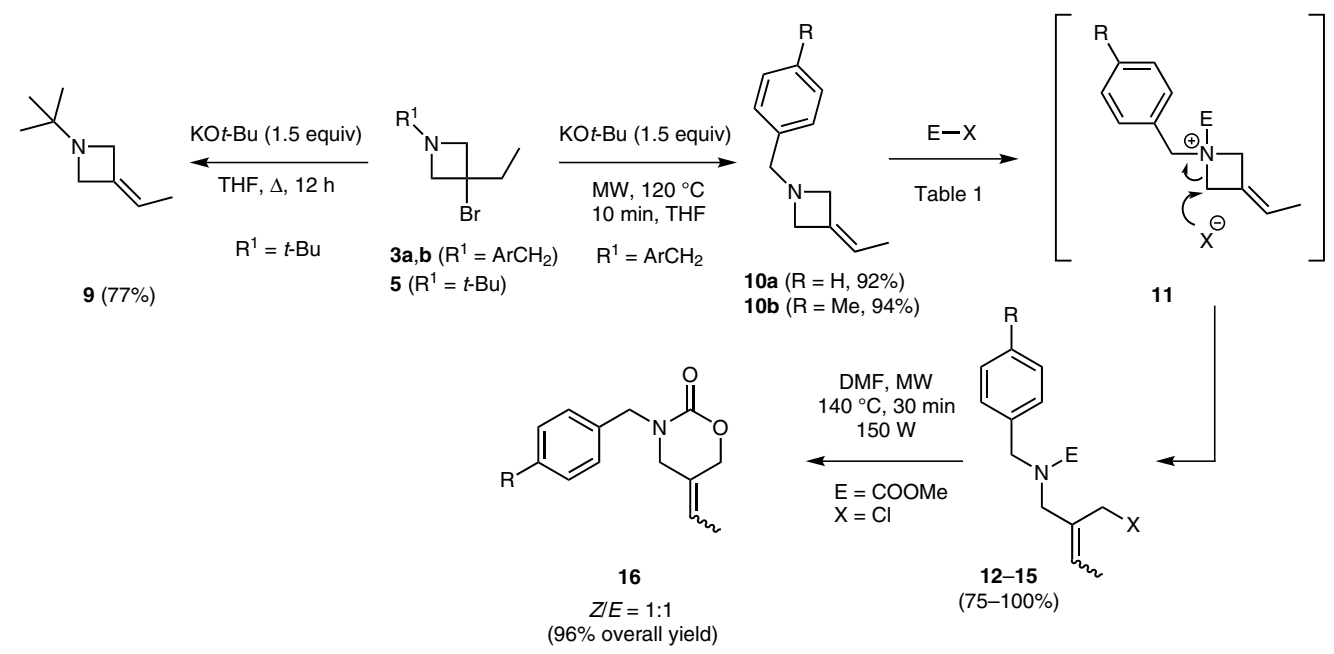

Scheme 3

chromatographically inseparable $E / Z$-mixtures were obtained. In addition, treatment of azetidines $\mathbf{1 0 a}, \mathbf{b}$ with 1.5 equivalents of methyl chloroformate in $\mathrm{MeCN}$ for 15 hours under reflux resulted in an $E / Z$-mixture of 4-aminobut-2-enes 14 ( $\mathrm{E}=\mathrm{COOMe}, \mathrm{X}=\mathrm{Cl}, E / Z=1: 1)$. Upon heating this mixture under microwave irradiation $\left(140^{\circ} \mathrm{C}\right.$, $30 \mathrm{~min}, 150 \mathrm{~W})$ in $\mathrm{DMF}$, the corresponding new cyclic carbamates 16 were obtained through 6-exo-tet cyclization. ${ }^{14}$ These cyclic carbamates can be regarded as interesting compounds with a variety of applications, most notably as precursors for $\gamma$-amino alcohols, ${ }^{15}$ as chiral auxiliaries, ${ }^{16}$ and as the core substructure in a number of biologically active compounds. ${ }^{17}$ When azetidine $\mathbf{1 0 a}$ was added to a mixture of 1.3 equivalents of benzyloxy- or methoxyacetyl chloride and three equivalents of $\mathrm{Et}_{3} \mathrm{~N}$ in $\mathrm{CH}_{2} \mathrm{Cl}_{2}$ and stirred at room temperature for 15 hours in an attempt to effect cycloaddition, the corresponding ringopened amides 15a,b $\left(\mathrm{E}=\mathrm{MeOCH}_{2} \mathrm{CO}\right.$ or $\mathrm{E}=$ $\left.\mathrm{BnOCH}_{2} \mathrm{CO}, \mathrm{X}=\mathrm{Cl}, E / Z=1: 1\right)$ were formed instead. Apparently, the initial attack of the nucleophilic nitrogen atom across the ketene formed in situ and subsequent ring opening of the azetidine moiety prevailed over the desired cycloaddition reaction.

The reactivity of 3-ethylideneazetidines $\mathbf{1 0}$ with respect to electrophilic additions across the exocyclic double bond was evaluated in the next phase of this work. Attempts to prepare halohydrins by treatment of azetidine 10a with one equivalent of NBS in water/THF (1:1) for ten minutes to two days proceeded sluggishly and gave complex mixtures. The outcome of this reaction was shown to be difficult to control and also dependent on the purity of NBS. On the other hand, selective access to the functionalized dibrominated azetidine $\mathbf{1 7}$ was achieved by the reaction of azetidine $10 \mathrm{a}$ with two equivalents of $\mathrm{NBS}$ in $\mathrm{CHCl}_{3}$ or $\mathrm{CH}_{2} \mathrm{Cl}_{2}$ under reflux for 15-24 hours. Apparently, the small amount of bromine, released from NBS, was able to react with azetidine 10a to afford 3-bromo-3-(1-bromoethyl)azetidine $17(\mathrm{X}=\mathrm{Br})$, although in variable yields (30-70\%) depending upon the purity of the NBS (Scheme 4). In another approach, the azetidine nitrogen atom was protonated by introducing gaseous $\mathrm{HCl}$ to the solution of azetidine $\mathbf{1 0 a}$ in $\mathrm{CH}_{2} \mathrm{Cl}_{2}$ for ten minutes, after which one equivalent of mCPBA was added. Instead of the expected spirocyclic azetidinyl epoxide 20a, 3-chloro-3-(1-chloroethyl)azetidine $18(\mathrm{X}=\mathrm{Cl})$ was obtained in $92 \%$ yield (Scheme 4), probably as the result of the electrophilic addition of in situ formed $\mathrm{Cl}_{2}$ to the double bond. ${ }^{18}$ The vicinal dihalogenated azetidines 17 and 18 were subsequently subjected to reactions with benzylamine or $\mathrm{KCN}$ in MeCN in the presence of a catalytic amount of $\mathrm{Ag}_{2} \mathrm{CO}_{3}$ or NaI. Unfortunately, these reactions resulted in

Table 1 Activation and Ring Opening of 3-Ethylideneazetidines 10a,b toward Functionalized Allylamines

\begin{tabular}{|c|c|c|c|c|}
\hline Substrate & Reaction conditions & $\mathrm{E}$ & $\mathrm{X}$ & Product (yield, E/Z) \\
\hline 10a & $\mathrm{AcCl}$ (1.5 equiv), $\mathrm{CH}_{2} \mathrm{Cl}_{2}, \Delta, 15 \mathrm{~h}$ & $\mathrm{MeCO}$ & $\mathrm{Cl}$ & $12(\mathrm{R}=\mathrm{H}, 100 \%, E / Z=1: 1)$ \\
\hline $10 \mathrm{a}$ & $\mathrm{BnBr}$ ( 1 equiv), $\mathrm{MeCN}, \Delta, 15 \mathrm{~h}$ & $\mathrm{Bn}$ & $\mathrm{Br}$ & $13(\mathrm{R}=\mathrm{H}, 100 \%, E / Z=3: 2$ or vice versa) \\
\hline 10a & ClCOOMe (1.5 equiv), $\mathrm{MeCN}, \Delta, 15 \mathrm{~h}$ & COOMe & $\mathrm{Cl}$ & $\mathbf{1 4 a}(\mathrm{R}=\mathrm{H}, 100 \%, E / Z=1: 1)$ \\
\hline 10b & ClCOOMe ( 1.5 equiv), $\mathrm{MeCN}, \Delta, 15 \mathrm{~h}$ & COOMe & $\mathrm{Cl}$ & $\mathbf{1 4 b}(\mathrm{R}=\mathrm{Me}, 100 \%, E / Z=1: 1)$ \\
\hline 10a & $\begin{array}{l}\mathrm{MeOCH}_{2} \mathrm{COCl}(1.3 \text { equiv) } \\
\mathrm{Et}_{3} \mathrm{~N} \text { ( } 3 \text { equiv), } \mathrm{CH}_{2} \mathrm{Cl}_{2} \text {, r.t., } 15 \mathrm{~h}\end{array}$ & $\mathrm{MeOCH}_{2} \mathrm{CO}$ & $\mathrm{Cl}$ & 15a $(\mathrm{R}=\mathrm{H}, 78 \%, E / Z=1: 1)$ \\
\hline 10a & $\begin{array}{l}\mathrm{BnOCH}_{2} \mathrm{COCl}(1.3 \text { equiv }) \\
\mathrm{Et}_{3} \mathrm{~N} \text { ( } 3 \text { equiv), } \mathrm{CH}_{2} \mathrm{Cl}_{2} \text {, r.t., } 15 \mathrm{~h}\end{array}$ & $\mathrm{BnOCH}_{2} \mathrm{CO}$ & $\mathrm{Cl}$ & $\mathbf{1 5 b}(\mathrm{R}=\mathrm{H}, 75 \%, E / Z=1: 1)$ \\
\hline
\end{tabular}




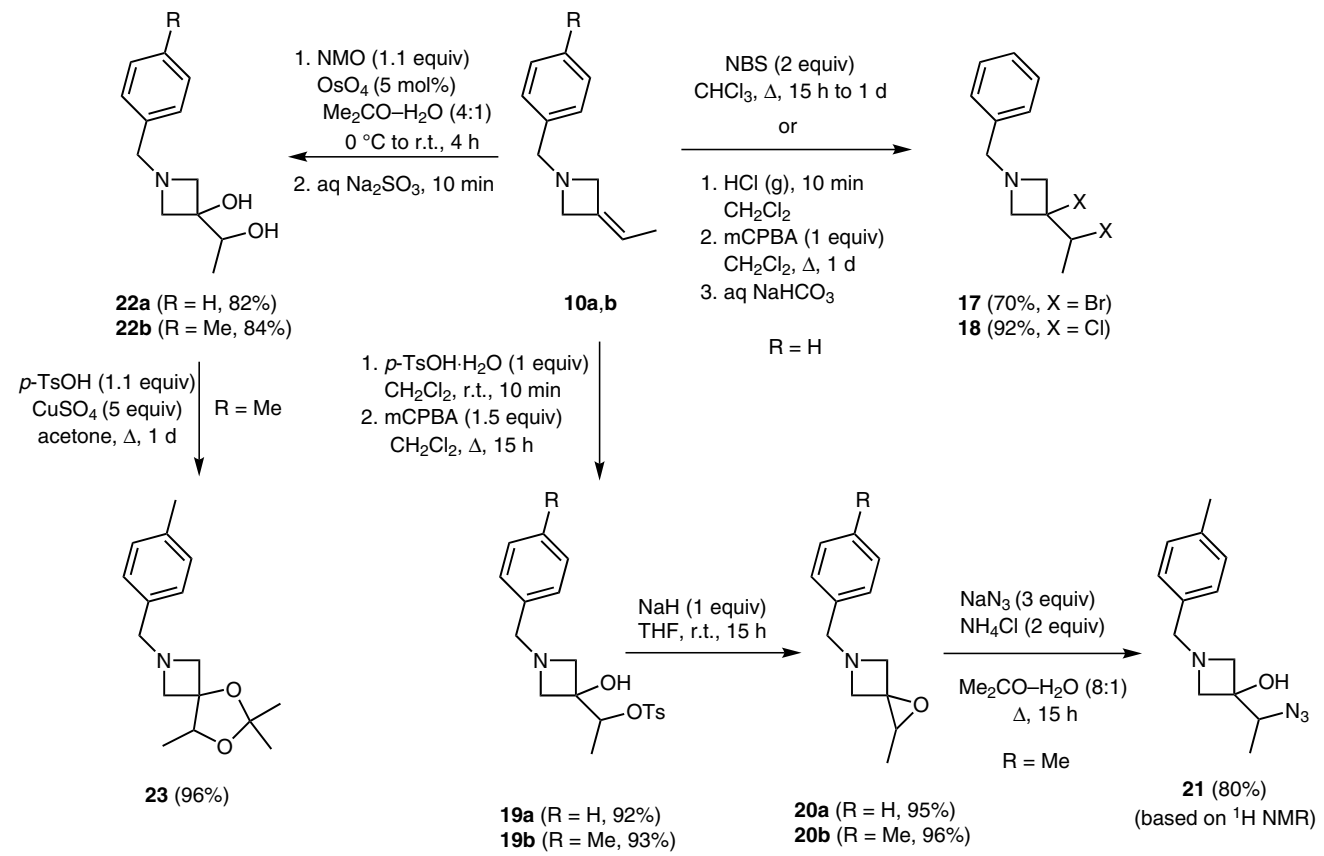

Scheme 4

the recovery of the starting materials or gave complex mixtures.

In a final attempt to produce the synthetically challenging spirocyclic azetidinyl epoxides $\mathbf{2 0}$, the azetidine nitrogen atom in structures $\mathbf{1 0}$ was protected by addition of one equivalent of $p$-TsOH in $\mathrm{CH}_{2} \mathrm{Cl}_{2}$. Subsequent addition of 1.5 equivalents of mCPBA and heating under reflux for 15 hours afforded highly unstable azetidin-3-ols 19a,b. However, immediate treatment of these alcohols 19 with one equivalent of $\mathrm{NaH}$ in THF for 15 hours at room temperature provided the target 1-oxa-5-azaspiro[2.3]hexanes 20a,b in excellent yields (Scheme 4). ${ }^{19}$ These novel strained spirocyclic systems showed a considerable stability as they could be purified by means of column chromatography on basic $\mathrm{Al}_{2} \mathrm{O}_{3}$ to provide analytically pure samples. The synthesis of the spiroazetidinyl epoxide moiety has received only very limited attention in the literature. ${ }^{20}$ However, these compounds have been shown to be useful intermediates for the preparation of different biologically active molecules. ${ }^{21}$ In general, the synthesis and reactivity of different azaspirocyclic scaffolds represent a challenging task for organic chemists and have lately been the subject of significant interest. ${ }^{20 a, 22}$

Bearing in mind that a number of azaspirocyles containing an azetidine moiety can be considered as structural surrogates of commonly employed saturated heterocycles with beneficial inherent structural features, further efforts were devoted to expand the family of novel spiroazetidine building blocks. By analogy with the epoxidation of azetidines 10, the direct aziridination of the double bond could provide an access to novel spirocyclic 1,5-diazaspiro[2.3] hexanes, ${ }^{23}$ although the treatment of azetidine 10a with NBS and Chloramine-T as nitrene precursor ${ }^{24}$ in MeCN afforded only small amounts of 3-bromo-3-(1-bro- moethyl)azetidine $\mathbf{1 7}$ and no traces of the corresponding spiro compounds. Using phenyltrimethylammonium tribromide (PTAB) and chloramine- $\mathrm{T}$ in $\mathrm{MeCN}$, a complex mixture was also obtained. ${ }^{25}$ An alternative route to the synthesis of the spiro-fused aziridinyl azetidine core structure could comprise the ring opening of epoxides 20 with an appropriate amine $\left(i-\mathrm{PrNH}_{2}\right)$ in the presence of $\mathrm{BF}_{3} \cdot \mathrm{OEt}_{2}$, followed by subsequent ring closure of the resulting amino alcohols under Mitsunobu conditions. Although the epoxide ring opening was shown to be successful, the drawback of this procedure involved the very low stability of the $\beta$-amino alcohol thus obtained, which underwent immediate decomposition. On the other hand, ring opening of epoxides $\mathbf{2 0}$ with three equivalents of $\mathrm{NaN}_{3}$ and two equivalents of $\mathrm{NH}_{4} \mathrm{Cl}$ in acetone/water (8:1) did afford the corresponding azide 21 after 15 hours under reflux (Scheme 4). However, the subsequent ring closure of 21 utilizing $\mathrm{Ph}_{3} \mathrm{P}$ in THF gave only complex reaction mixtures. In addition, dihydroxylation of the double bond in azetidines $\mathbf{1 0 a}, \mathbf{b}$ with 1.1 equivalents of $N$-methylmorpholine- $N$-oxide (NMO) and $\mathrm{OsO}_{4} \quad(5$ $\mathrm{mol} \%$ ) in acetone/water (4:1) for four hours at room temperature, followed by an aqueous workup, furnished dihydroxyazetidines $\mathbf{2 2 a} \mathbf{a}, \mathbf{b}$ in good yields (Scheme 4 ). In order to provide an entry to a different class of azaspirocyclic building blocks, azetidine 22b was treated with 1.1 equivalents of $p$ - TsOH and five equivalents of $\mathrm{CuSO}_{4}$ in acetone to afford the corresponding novel 5,7-dioxa-2azaspiro[3.4] octane $\mathbf{2 3}$ after stirring under reflux for one day (Scheme 4). This spirocyclic core structure has been found to be present in a number of spiro lactams, suitable for further chemical transformations. ${ }^{26}$

In conclusion, 3-bromo-3-ethylazetidines have been shown to undergo ready nucleophilic substitution with 
different nucleophiles, providing a convenient method for the preparation of new 3-alkoxy-, 3-aryloxy-, 3-acetoxy-, 3-hydroxy-, 3-cyano-, 3-carbamoyl- and 3-amino-3-ethylazetidines. Furthermore, 3-bromo-3-ethylazetidines can be used as suitable substrates for the preparation of 3-ethylideneazetidines which, in spite of the presence of a rather inactive double bond, were shown to represent valuable compounds for the preparation of novel functionalized azetidines and spirocyclic azetidine building blocks.

\section{References and Notes}

(1) Present address: Department of Chemistry, Faculty of Science, University of Antwerp, Middelheimcampus, G.V.211, Groenenborgerlaan 171, 2020 Antwerp, Belgium.

(2) (a) Tanner, D. Angew. Chem., Int. Ed. Engl. 1994, 33, 599. (b) Osborn, H. M. I.; Sweeney, J. Tetrahedron: Asymmetry 1997, 8, 1693. (c) Sweeney, J. B. Chem. Soc. Rev. 2002, 31, 247. (d) Singh, G. S.; D'hooghe, M.; De Kimpe, N. Chem. Rev. 2007, 107, 2080. (e) Stanković, S.; D’hooghe, M.; Catak, S.; Eum, H.; Waroquier, M.; Van Speybroeck, V.; De Kimpe, N.; Ha, H.-J. Chem. Soc. Rev. 2012, 41, 643. (f) Couty, F. In Science of Synthesis; Vol. 40a; Enders, D., Ed.; Georg Thieme Verlag: Stuttgart, 2009, 773-817. (g) Couty, F.; Durrat, F.; Evano, G. Targets Heterocycl. Syst. 2005, 9, 186. (h) Yadav, L. D. S.; Srivastava, V. P.; Patel, R. Tetrahedron Lett. 2008, 49, 5652. (i) Van Brabandt, W.; Mangelinckx, S.; D'hooghe, M.; Van Driessche, B.; De Kimpe, N. Curr. Org. Chem. 2009, 13, 829. (j) Brandi, A.; Cicchi, S.; Cordero, F. M. Chem. Rev. 2008, 108, 3988. (k) Bott, M. T.; West, F. G. Heterocycles 2012, 84, 223. (l) Couty, F.; Drouillat, B.; Evano, G.; David, O. Eur. J. Org. Chem. 2013, 2045. (m) Mangelinckx, S.; Žukauskaite, A.; Buinauskaitė, V.; Šačkus, A.; De Kimpe, N. Tetrahedron Lett. 2008, 49, 6896. (n) Žukauskaite, A.; Mangelinckx, S.; Buinauskaitè, V.; Šačkus, A.; De Kimpe, N. Amino Acids 2011, 41, 541 .

(3) (a) Cromwell, N. H.; Phillips, B. Chem. Rev. 1979, 79, 331. (b) Moore, J. A.; Ayers, R. S. Chemistry of Heterocyclic Compounds-Small Ring Heterocycles; Hassner, A., Ed.; Wiley: New York, 1983, Part 2 1-217. (c) Davies, D. E.; Storr, R. C. Comprehensive Heterocyclic Chemistry; Vol. 7, Part 5; Lwowski, W., Ed.; Pergamon: Oxford, 1984, $237-$ 284. (d) De Kimpe, N. Three- and Four-Membered Rings, With All Fused Systems Containing Three- and FourMembered Rings, In Comprehensive Heterocyclic Chemistry II; Vol. 1; Padwa, A., Ed.; Chap. 1.21; Elsevier: Oxford, 1996.

(4) (a) Ojima, I.; Zhao, M.; Yamato, T.; Nakahashi, K. J. Org. Chem. 1991, 56, 5263. (b) Van Brabandt, W.; Dejaegher, Y.; Van Landeghem, R.; De Kimpe, N. Org. Lett. 2006, 8, 1101. (c) Van Brabandt, W.; Van Landeghem, R.; De Kimpe, N. Org. Lett. 2006, 8, 1105.

(5) (a) Sulmon, P.; De Kimpe, N.; Schamp, N. J. Chem. Soc., Chem. Commun. 1985, 715. (b) Sulmon, P.; De Kimpe, N.; Schamp, N.; Tinant, B.; Declercq, J.-P. Tetrahedron 1988, 44, 3653. (c) Aelterman, W.; De Kimpe, N.; Declercq, J.-P. J. Org. Chem. 1998, 63, 6.

(6) (a) Dejaegher, Y.; Mangelinckx, S.; De Kimpe, N. J. Org. Chem. 2002, 67, 2075. (b) Colpaert, F.; Mangelinckx, S.; De Brabandere, S.; De Kimpe, N. J. Org. Chem. 2011, 76, 2204. (c) Colpaert, F.; Mangelinckx, S.; De Kimpe, N. Org. Lett. 2010, 12, 1904.

(7) (a) Marehand, A. P.; Ramanaiah, K. C. V.; Bott, S. G.; Gilbert, J. C.; Kirschner, S. Tetrahedron Lett. 1996, 37, 8101. (b) Collier, P. N. Tetrahedron Lett. 2009, 50, 3909. (c) Hanessian, S.; Fu, J.-M.; Chiara, J.-L.; Di Fabio, R. Tetrahedron Lett. 1993, 34, 4157. (d) Marehand, A. P.; Devasagayaraj, A. J. Org. Chem. 1997, 62, 4434.

(e) Burtoloso, A. C. B.; Correia, C. R. D. Tetrahedron 2008, 64,9928

(8) (a) Hanessian, S.; Fu, J.-M.; Tu, Y. Tetrahedron Lett. 1993, 34, 4153. (b) Emmer, G. Tetrahedron 1992, 48, 7165. (c) Liang, Y.; Raju, R.; Le, T.; Taylor, C. D.; Howell, A. R. Tetrahedron Lett. 2009, 50, 1020.

(9) (a) Stanković, S.; D’hooghe, M.; Abbaspour Tehrani, K.; De Kimpe, N. Tetrahedron Lett. 2012, 53, 107. (b) Van Driessche, B.; Van Brabandt, W.; D'hooghe, M.; Dejaegher, Y.; De Kimpe, N. Tetrahedron 2006, 62, 6882.

(10) (a) Abbaspour Tehrani, K.; De Kimpe, N. Curr. Org. Chem. 2009, 13, 854. (b) Mangelinckx, S.; Boeykens, M.; De Kimpe, N. Synlett 2008, 1394. (c) Lu, H.; Li, C. Org. Lett. 2006, 8, 5365. (d) Sulmon, P.; De Kimpe, N.; Schamp, N. J. Org. Chem. 1988, 53, 4462. (e) De Kimpe, N.; Boeykens, M. J. Org. Chem. 1994, 59, 5189. (f) De Kimpe, N.; Boeykens, M. J. Org. Chem. 1994, 59, 5189. (g) Abbaspour Tehrani, K.; De Kimpe, N. Tetrahedron Lett. 2000, 41, 1975.

(11) Cainelli, G.; Giacomini, D.; Gazzano, M.; Galletti, P.; Quintavalla, A. Tetrahedron Lett. 2008, 49, 5652.

(12) (a) Stanković, S.; Goossens, H.; Catak, S.; Tezcan, M.; Waroquier, M.; Van Speybroeck, V.; D'hooghe, M.; De Kimpe, N. J. Org. Chem. 2012, 77, 3181. (b) Stanković, S.; Catak, S.; D'hooghe, M.; Goossens, H.; Abbaspour Tehrani, K.; Bogaert, P.; Waroquier, M.; Van Speybroeck, V.; De Kimpe, N. J. Org. Chem. 2011, 76, 2157.

(13) 3-Ethylidene-1-(4-methylbenzyl)azetidine (10b): To an icecooled solution of 3-bromo-3-ethyl-1-(4-methylbenzyl)azetidine (3b; $1.34 \mathrm{~g}, 5 \mathrm{mmol})$ in anhyd THF $(30 \mathrm{~mL})$, $t$-BuOK ( $0.84 \mathrm{~g}, 1.5$ equiv) was added and the mixture was subjected to microwave heating $(150 \mathrm{~W})$ for $10 \mathrm{~min}$ at $120^{\circ} \mathrm{C}$. Afterwards, the reaction mixture was cooled to r.t., filtered, poured into $\mathrm{H}_{2} \mathrm{O}(20 \mathrm{~mL})$ and extracted with $\mathrm{Et}_{2} \mathrm{O}(3$ $\times 20 \mathrm{~mL})$. The combined organic extracts were washed with $\mathrm{H}_{2} \mathrm{O}(2 \times 15 \mathrm{~mL})$ and brine $(20 \mathrm{~mL})$. Drying $\left(\mathrm{MgSO}_{4}\right)$, filtration of the drying agent and evaporation of the solvent in vacuo afforded azetidine $\mathbf{1 0 b}(0.88 \mathrm{~g}, 94 \%)$, which was purified by silica gel column chromatography to obtain an analytically pure sample; pale yellow oil; $R_{f} 0.22$ (petroleum ether-EtOAc, 4:1); yield: 94\%. ${ }^{1} \mathrm{H}$ NMR $(300 \mathrm{MHz}$, $\left.\mathrm{CDCl}_{3}\right): \delta=1.46-1.51(\mathrm{~m}, 3 \mathrm{H}), 2.33(\mathrm{~s}, 3 \mathrm{H}), 3.68(\mathrm{~s}, 2 \mathrm{H})$, 3.79-3.82 (m, $4 \mathrm{H}), 5.16-5.24(\mathrm{~m}, 1 \mathrm{H}), 7.11-7.14,7.18-$ $7.21(\mathrm{~m}, 4 \mathrm{H}) .{ }^{13} \mathrm{C}$ NMR $\left(75 \mathrm{MHz}, \mathrm{CDCl}_{3}\right): \delta=13.6,21.2$, $60.8,62.2,63.5,115.1,128.5,129.1,131.8,135.7,136.7$. IR (neat): $2917,2805,1514,1439,1358,1273,1176,1042$, 1021, 806, 780, $753 \mathrm{~cm}^{-1}$. MS: $m / z(\%)=188(100)\left[\mathrm{M}^{+}+\right.$ 1]. HRMS (ESI): $m / z[\mathrm{M}+\mathrm{H}]^{+}$calcd for $\mathrm{C}_{13} \mathrm{H}_{18} \mathrm{~N}: 188.1434$; found: 188.1435 .

(14) Ma, S.; Yoon, D. H.; Ha, H.-J.; Lee, W. K. Tetrahedron Lett. 2007, 48, 269.

(15) (a) Fujiwara, M.; Baba, A.; Matsuda, H. J. Heterocycl. Chem. 1989, 26, 1659. (b) Shibata, I.; Nakamura, K.; Baba, A.; Matsuda, H. Bull. Chem. Soc. Jpn. 1989, 62, 853. (c) Baba, A.; Shibata, I.; Fujiwara, M.; Matsuda, H. Tetrahedron Lett. 1985, 26, 5167. (d) Rice, G. T.; White, M. C. J. Am. Chem. Soc. 2009, 131, 11707. (e) Nahra, F.; Liron, F.; Prestat, G.; Mealli, C.; Messaoudi, A.; Poli, G. Chem. Eur. J. 2009, 15, 11078. (f) Mangelinckx, S.; Nural, Y.; Dondas, H. A.; Denolf, B.; Sillanpää, R.; De Kimpe, N. Tetrahedron 2010, 66, 4115.

(16) Davies, S. G.; Garner, A. C.; Robert, P. M.; Smith, A. D.; Sweet, M. J.; Thomson, J. E. Org. Biomol. Chem. 2006, 4, 2753. 
(17) (a) Park, M.; Lee, J. Arch. Pharmacol. Res. 1993, 16, 158. (b) Li, X.; Wang, R.; Wang, Y.; Chen, H.; Li, Z.; Ba, C.; Zhang, J. Tetrahedron 2008, 64, 9911. (c) McElroy, C. R.; Aricò, F.; Benetollo, F.; Tundo, P. Pure Appl. Chem. 2012, 84, 707. (d) Wang, G.; Ella-Menye, J.-R.; Sharma, V. Bioorg. Med. Chem. Lett. 2006, 16, 2177.

(18) Podgoršek, A.; Iskra, J. Molecules 2010, 15, 2857.

(19) 5-Benzyl-2-methyl-5-aza-1-oxaspiro[2.3] hexane (20a): To an ice-cooled solution of 1-benzyl-3-hydroxy-3-(1-tosyloxyethyl)azetidine (19a; $0.19 \mathrm{~g}, 0.5 \mathrm{mmol})$ in anhyd THF $(15 \mathrm{~mL}), \mathrm{NaH}$ (60\% suspension; $0.02 \mathrm{~g}, 1$ equiv) was slowly added and the mixture was stirred for $15 \mathrm{~h}$ at r.t. The reaction mixture was poured into $\mathrm{H}_{2} \mathrm{O}(20 \mathrm{~mL})$ and extracted with $\mathrm{Et}_{2} \mathrm{O}(3 \times 20 \mathrm{~mL})$. The combined organic extracts were washed with $\mathrm{H}_{2} \mathrm{O}(2 \times 15 \mathrm{~mL})$ and brine $(20 \mathrm{~mL})$. Drying $\left(\mathrm{MgSO}_{4}\right)$, filtration of the drying agent and evaporation of the solvent in vacuo afforded spirocycle $20 \mathrm{a}(0.10 \mathrm{~g}, 95 \%)$, which was purified by means of column chromatography on basic alumina in order to obtain an analytically pure sample; pale yellow oil; $R_{f} 0.22$ (petroleum ether-EtOAc, $4: 1$ ); yield: 95\%. ${ }^{1} \mathrm{H}$ NMR $\left(300 \mathrm{MHz}, \mathrm{CDCl}_{3}\right): \delta=1.23(\mathrm{~d}, J=5.5 \mathrm{~Hz}$, $3 \mathrm{H}), 3.07(\mathrm{q}, J=5.5 \mathrm{~Hz}, 1 \mathrm{H}), 3.35-3.38,3.43-3.46(2 \times \mathrm{m}$, $2 \mathrm{H}), 3.60-3.66$ (m, $2 \mathrm{H}), 3.76$ (s, $2 \mathrm{H}), 7.23-7.36$ (m, $5 \mathrm{H})$. ${ }^{13} \mathrm{C}$ NMR $\left(75 \mathrm{MHz}, \mathrm{CDCl}_{3}\right): \delta=15.5,56.2,59.5,60.4,61.6$, 64.1, 127.3, 128.6, 138.2. IR (neat): 2925, 2831, 1495, 1453, 1363, 1161, 826, 725, $697 \mathrm{~cm}^{-1}$. MS: $m / z(\%)=190(100)$ $\left[\mathrm{M}^{+}+1\right]$. HRMS (ESI): $m / z[\mathrm{M}+\mathrm{H}]^{+}$calcd for $\mathrm{C}_{12} \mathrm{H}_{15} \mathrm{NO}$ : 190.1232; found: 190.1232 .
(20) (a) Guérot, C.; Tchitchanov, B. H.; Knust, H.; Carreira, E. M. Org. Lett. 2011, 13, 780. (b) Marehand, A. P.; Devasagayaraj, A. Heterocycles 1998, 49, 149.

(21) (a) Lamb, P. PCT Int. Appl 2008076415, 2008. (b) Aay, N.; Anand, N. K.; Bowles, O. J.; Bussenius, J.; Costanzo, S.; Curtis, J. K.; Dubenko, L.; Joshi, A. A.; Kennedy, A. R.; Kim, A. I.; Koltun, E.; Manalo, J.-C. L.; Peto, C. J.; Rice, K. D.; Tsang, T. H. PCT Int. Appl 2007044515, 2007.

(22) (a) Burkhard, J. A.; Guérot, C.; Knust, H.; Rogers-Evans, M.; Carreira, E. M. Org. Lett. 2010, 12, 1944. (b) Meyers, M. J.; Muizebelt, I.; van Wiltenburg, J.; Brown, D. L.; Thorarensen, A. Org. Lett. 2009, 11, 3523. (c) Burkhard, J. A.; Guérot, C.; Knust, H.; Carreira, E. M. Org. Lett. 2012, 14, 66. (d) Li, D. B.; Rogers-Evans, M.; Carreira, E. M. Org. Lett. 2011, 13, 6134.

(23) Žukauskaitè, A.; Mangelinckx, S.; Callebaut, G.; Wybon, C.; Šačkus, A.; De Kimpe, N. Tetrahedron 2013, 69, 3437.

(24) Thakur, V. V.; Sudalai, A. Tetrahedron Lett. 2003, 44, 989.

(25) Sureshkumar, D.; Maity, S.; Chandrasekaran, S. J. Org. Chem. 2006, 71, 1653.

(26) (a) Alcaide, B.; Almendros, P.; Aragoncillo, C.; Cabrero, G.; Callejo, R.; Ruiz, M. P. Eur. J. Org. Chem. 2008, 4434.

(b) Simone, M. I.; Edwards, A. A.; Tranter, G. E.; Fleet, G. W. J. Tetrahedron: Asymmetry 2008, 19, 2887.

(c) Chincholkar, P. M.; Kale, A. S.; Gumaste, V. K.; Rakeeb, A.; Deshmukh, A. S. Tetrahedron 2009, 65, 2605.

(d) Grochowskit, E.; Gluziliski, P.; Krajewski, J. W.; Pupek, K. J. Mol. Struct. 1992, 269, 141. 